Alberto Vjada Lozano - Disquisición en Torno a la Extinción del Derecho del...

\title{
DISQUISICIÓN EN TORNO A LA EXTINCIÓN DEL DERECHO DEL. ARRENDADOR
}

\author{
Alberto Viada Lozano \\ Profesor de Derecho Comercial \\ Universidad Católica del Norte \\ Sede Coquimbo
}

Ocurre, con más frecuencia que la deseada, que algunos comerciantes se ven obligados a restituir el local en que funciona su establecimiento de comercio, pues el arrendador propietario lo vende a un tercero y éste reclama judicialmente dicho inmueble alegando la extinción del derecho del arrendador. Ello porque, según el texto expreso del artículo 1950 del Código Civil, "el arrendamiento de cosas expira de los mismos modos que los otros contratos, y especialmente:....3 $3^{\circ}$ Por la extinción del derecho del arrendador, según las reglas que más adelante se expresarán"

Una primera inquietud surge de la circunstancia que la misma disposición citada agrega, en su número $4^{2}$, que es también otro modo especial de expirar el contrato de a rrendamiento: "Por sentencia del juez en los casos que la ley ha previsto". ¿Significa ello que, por ende, la expiración del arriendo por extinción del derecho del arrendador opera por el solo ministerio de la ley?, ¿que no necesita sentencia de juez para que se termine el contrato de arrendamiento?. Ahonda esta inquietud lo dispuesto en el N 4 del articulo $7^{0}$ de la ley 18.101, que fija normas especiales sobre arrendarniento de predios urbanos, donde se establece que las reglas de competencia y procedimiento del Títula IJI de dicha ley, "deberán aplicarse, en especial, a los juicios siguientes.... 4. Restitución de la propiedad por extinción del derecho del arrendador", que pareciera presuponer que el contrato de arrendamiento habría terminado por el solo hecho de haberse extinguido el derecho del arrendador, quedándole al tercero adquirente de ese derecho sola mente exigir la restitución del inmueble arrendado.

Espero que en el curso de esta diquisición quedarán suficientemente dilucidadas estas interrogantes. De antemano, pienso que el término del contrato por esta causal no se produce ipso jure, sino que el tercero deberá demandar dos pretensiones, sujetas al mismo procedimiento. La primera, la "terminación del arrendamiento", obviamente por la causal de extinción del derecho del arrendador, juício contemplado en el $\mathrm{N}^{\mathrm{a}} 2$ del artículo $7^{2}$ citado, y la atra pretensión será la de "restitución" del inmueble, precisamente porque se declarará o se declaró terminado el contrato por dicho modo. $Y$ a mbas pretensiones podrá demandarlas conjuntamente en un mismo proceso, puesto que el artículo 17 del Código de Procedimiento Civil es meridiano al disponer que, "en un mismo juicio podrán entablarse dos o más acciones con tal que no sean incompatibles". 

Alberto Viada Lozano. Disquisición en Torno a la Extinción del Derecho del...

título lucrativo; $2^{2}$ Todo aquel a quien se transfiere el derecho del arrendador a título oneroso, si el arrendamiento ha sido contraído por escritura pública; exceptuádos los acreedores hipotecarios; $3^{2}$ Los acreedores hipotecarios, si el arrendamiento ha sido otorgado por escritura pública inscrita en el Registro del Conservador antes de la inscripción hipotecaria".

Queda claro, entonces, que el modo de expirar el arriendo en estudio sólo opera en los casos en que el arrendador es titular de un "derecho real" sobre la cosa arrendada y ha contratado cediendo el goce de dicho bien. También queda claro que la terminación del contrato de arriendo por esta causal no puede operar de pleno derecho, puesto que deberá determinarse judicialmene si el contrato de arrendamiento subsiste a pesar de la extinción del derecho del arrendador, si debe ser respetado; o si, por el contrario tal extinción del derecho real acarrea también la expiración del contrato de arrendamiento $y$, por ende, de los derechos personales del arrendador y del arrendatario.

\section{IV}

Naturalmente que será el tercero adquirente del derecho real del arrendador quien estará interesado en que se declare la expiración del arriendo contratado sobre la cosa adquirida. Y la demanda que entable corresponderá al ejercicio del "derecho real" que ha sido adquirido o recuperado, para que se declare terminado el contrato de arrendamiento que impide, entraba o perturba su ejercicio del referido "derecho real". No puede ejercer su acción demandando pretensiones correspondientes a los derechos personales que emanan del contrato de arrendamiento; puesto que no es parte de dicho contrato, y el artículo 1.545 del Código Civil es meridiano al declarar que "todo contrato legalmente celebrado es una ley para los contratantes...", no para terceros adquirentes del bien objeto del contrato. Ergo, salvo cesión en forma, el adquirente del derecho real carece de acción para impetrar las cláusulas del contrato de arriendo y las normas legales supletorias de la voluntad de las partes, sino que solamente podrá ejercer la acción judicial en que pretenda lo propio de su "derecho real", como, por ejemplo, que se declare terminado el contrato de arrendamiento que le impide ejercer cabalmente todas las facultades propias de ese derecho real.

En consecuencia, puesto que el tercero adquirente del derecho real sólo puede ejercer su acción pretendiendo su derecho sobre la cosa arrendada, no. los derechos personales que emanan del contrato de arrendamiento, tal demanda deberá entablarla contra el arrendador, ya que el inciso primero del artículo 1931 del Código Civil es meridiano al establecer que "la acción de terceros que pretendan derecho a la cosa arrendada, se dirigirá contra el arrendador". Respecto a la pretensión a que se refiere esta disposición legal, es bueno recordar algunos conceptos vertidos por el catedrático de Derecho Procesal de la Universidad de Madrid don Jaime Guasp, en una monografía. sobre "La pretensión procesal". Dice así:

"La pretensión procesal, ejercicio de la acción o derecho previo al proceso, se deduce en éste simultáneamente o no con la demanda, determinando de un lado el ámbito verdadero dentro del que el proceso vive, de otro, el centro de referencia al que el desarrollo procesal se remite. El binomio conceptual: acción - demanda, se resuelve, pues, más certeramente, en un trinomio: acción- pretensión-demanda...". "La idea fundamental a este respecto puede resumirse así: concedido por el Estado el poder de. 
acudir a los Tribunales de Justicia para formular pretensiones (derecho de acción), el particular puede reclamar cualquier bien de la vida frente a otro sujeto distinto de un órgano estatal (pretensión procesal), iniciando para ello el correspondiente proceso (demanda)..."

"En definitiva, queda así establecido que la pretensión procesal, por su estruc.tura, es una declaración de voluntad por la cual una persona reclama de otra, ante un tercero supraordinado a ambas; un bien de la vida, formulando en torno al mismo una petición fundada, esto es, acotada o delimitada, según los acaecimientos de hecho que expresamente se señalen". .

En el caso en estudio, entonces, el tercero pretenderá el derecho real que adquirió o recuperó sobre la cosa arrendada, solicitando que se declare expirado el contrato de arrendamiento que le impide el ejercicio pleno de ese derecho real. $Y$ esta pretensión deberá dirigirla precisamente contra el arrendador, de quien proviene el derecho real que adquirió o recuperó, conforme lo ordena el inciso primero del artículo 1931 del Código Civil, ya transcrito. En cuanto al arrendatario, deberá también demandarlo para la restitución de la cosa arrendada, puesto que es él quien la detenta, sea quie entable conjuntamente el juicio de restitución con el de terminación de arriendo, lo que vimos que era posible conforme al artículo 17 del Código de Procedimiento Civil y lo dispuesto en el artículo 18 del mismo Código, al decir este último que, "en un mismo juicio, podrán intervenir como demandantes o demandados varias personas, siempre que se deduzca la misma acción o acciones que emanen directa e inmediatamente de un mismo hecho..."; o que lo entable con posterioridad a la declaración del tribunal que de por expirado el contrato de arrendamiento.

\section{V}

Ahora bien, ¿qué derechos tiene el arrendatario frente a esta eventual terminación del contrato de arrendamiento por la extinción del derecho real que detentaba el arrendador? Porque el № 3 del artículo 1.924 del Código Civil establece claramente que "el arrendador es obligado:... $3^{0}$ A librar al arrendatario a toda turbación o embarazo en el goce de la cosa arrendada". Una primera norma de aplicación de esta obligación y, consecuentemente, del derecho correspondiente del arrendatario, aparece en el artículo 1.930 del Código Civil, que señala que "si el arrendatario, por consecuencia de los derechos que ha justificado un tercero, se hallare privado de tanta parte de la cosa arrendada, que sea de presumir que sin esa parte no habría contratado...podrá exigir indemnización de todo perjuicio, si la causa del derecho justificado por el tercero fue o debió ser conocida del arrendador al tiempo del contrato, pero no lo fue del arrendatario...". Por su parte, el artículo 1.959 dispone que, si teniendo el arrendador una calidad particular que hace incierta la duración de su derecho, "hubiere arrendado como propietario absoluto, será obligado a indemnizar al arrendatario; salvo que éste haya contratado a sabiendas de que el arrendador no era propietario absoluto". Y el artículo 1.961 agrega: "Extinguiéndose el derecho del arrendador por hecho o culpa suyos, como cuando vende la cosa arrendada de que es dueño...será obligado a indemnizar al arrendatario en todos los casos en que la persona que le sucede en el derecho no esté obligada a respetar el arriendo ".

En otras palabras, el arrendador es responsable de sanear la evicción que pudiera sufrir el arrendatario, precisamente porque la ley lo obliga a librarle de toda turbación o 
Alberto Viada Lozano - Disquisición en Torno a la Extinción del Derecho del...

embarazo en el goce de la cosa arrendada. Aplicando al contrato de arrendamiento la definición del artículo 1.838 del Código Civil, "hay evicción de la cosa arrendada cuando el arrendatario es privado de todo o parte de ella por sentencia judicial". Esta institución no es exclusiva de la compraventa: "La responsabilidad o prestación de la evicción, es una circunstancia natural en todos los contratos onerosos, cuando el que recibió alguna cosa se le quita o embaraza su uso por otro, en cuyo caso podrá recurrir contra el que se la dio para que se la sanee. Tiene pues lugar: $-1^{\circ}$ en las ventas; $-2^{\circ}$ en las permutas; $-3^{\circ}$ en los arrendamientos; $-4^{\circ}$ en la dación en pago de deudas..." . (Joaquin Escriche. "Diccionario Razonadó de Legislación Civil; Penal, Comercial y Foren-

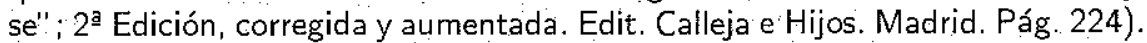

Y ¿cómo opera este saneamiento de evicción en el contrato de arrendamiento, cuando éste termina por extinción del derecho real del arrendador sobre la cosa arrendada? En primer lugar, ya vimos que la evicción es la privación de la cosa arrendada por sentencia judicial; por lo que se requiere de un juicio. También vimos que el tercero que recuperó o adquirió el derecho real sobre la cosa arrendada debe entablar su demanda contra el arrendador, conforme a lo dispuesto en el inciso primero del artículo 1.931 del Código Civil, lo que resulta justo, puesto que es él quien debe librar al arrendatario de toda turbación o embarazo en el goce de la cosa arrendada. $Y$ si, erróneamente en mi concepto, entablare la demanda solamente en contra del arrendatario, el inciso segundo de la disposición citada señala el trámite a seguir: "El arrendatario será sólo obligado a noticiarle la turbación o molestia que recibe de dichos terceros, por consecuencia de los derechos que alegan, y si lo omitiere o dilatare culpablemente, abonará los perjuicios de que ello se sigan al arrendador ". O, dicho de otro modo, habiéndose demandado solamente al arrendatario para que se termine el contrato de arrendamiento por el derecho real adquirido o recuperado por el demandante, el que se habría extinguido respecto del arrendador, si el demandado no citare la evicción del arrendador, perderá sus derechos a ser indemnizado por tal evicción, pues sus perjuicios sufrirán una especie de compensación con los que de ello se siguieren al arrendador. Ello es en todo similar a la evicción en el contrato de compraventa, en el que el comprador a quien se demanda la cosa vendida deberá citar al vendedor para que comparezca a defenderla, citación que se hará en el tiempo y forma previstos en el Título $V$ del Libro III del Código de Procedimiento Civil, y, "si el comprador omitiere citarle, y fuere evicta la cosa, el vendedor no será obligado al saneamiento; y si el vendedor citado no compareciere a de fender la cosa vendida, será responsable de la evicción...". (inc. 30 Artículo. 1.843 del C. Civil).

En relación a lo expuesto en los tres párrafos precedentes, me permito citar lo siguiente: "Pero cuando la pretenșión es de derecho (pretende ser dueño o acreedor hipotecario o se cree con derecho a una servidumbre), entonces si que responde el arrendador, $y$, de acuerdo con el artículo 1.931, debe seguirse el juicio contra el arrendador y no contra el arrendatario". "En realidad, estos artículos 1.930 y 1.931 contemplan la evicción en el contrato de arrendamiento". (Arturo Alessandri Rodríguez y Manuel Somarriva Undurraga; "Curso de Derecho Civil", Editorial Nascimiento, 1942, Pág. 458).

Recapitulando y aplicando armónicamente todas las disposiciones legales correspondientes, si solamente el arrendatario es demandado para que se declare expirado el contrato de arrendamiento por extinción del derecho del arrendador, el arrendatario demandado deberá citar de evicción al arrendador, antes de la contestación de la de- 
manda, y decretada la citación se suspenderá la tramitación del juicio para notificar al citado de evicción, quien deberá comparecer dentro del término de emplazamiento para defender y librar al arrendatario de la privación, turbación o embarazo en el goce de la cosa arrendada, y, compareciendo, se seguirá contra él solo la demanda, pero el arrendatario podrá siempre intervenir en el juicio para la conservación de sus derechos, y si el arrendador no comparece o, compareciendo, es evicta la cosa arrendada, deberá responder de los perjuicios que esa evicción acarreará al arrendatario.

Una incertidumbre sobre la aplicación cabal de la evicción al caso en estudio derivaría de la interpretación analógica del artículo 1.839 del Código Civil, que dispone: "El vendedor es obligado a sanear al comprador todas las evicciones que tengan una causa anterior a la venta, salvo en cuanto se haya estipulado lo contrario". Ello, traspasado al arrendamiento, haría parecer que el saneamiento de evicción sólo sería aplicable a los casos en que la extinción del derecho del arrendador sobre la cosa arrendada se produjere por la llegada del día en que debe cesar el usufructo, o pasar la propiedad al fideicomisario, o cuando su derecho esté sujeto a condición resolutoria; pero no procedería cuando se extinguiere dicho derecho real por hecho o culpa del arrendador, como cuando vende la cosa arrendada de que es dueño, o siendo usufructuario de ella hace cesión del usufructo al propietario, o pierde la propiedad por no haber pagado el precio de venta.

En mi opinión, la norma del artículo 1.839 transcrito significa que "siempre" habrá lugar al saneamiento de evicción cuando la causa de ella sea anterior al contrato, pero si la causa fuere ulterior, habría que determinar si se debió a hecho o culpa del vendedor o arrendador para establecer su responsabilidad de sanear. Además, debe considerarse la diferente naturaleza de los contratos, pues mientras el de compraventa es de efectos únicos e inmediatos, el de arrendamiento es de tracto sucesivo, lo que obliga al arrendador a librar al arrendatario, durante toda la vigencia del arriendo, de toda privación, turbación o embarazo en el goce de la cosa arrendada, y, por ende, a sanearle la evicción aunque ella se produzca por causa posterior a la celebración del contrato.

\section{VI}

Otro problema digno de ser analizado tiene relación con los efectos del contrato de arrendamiento en el período que media entre que se produce la extinción del derecho real del arrendador sobre la cosa arrendada y aquél en que se declara terminado el contrato de arrendamiento por dicha causal. ¿Qué pasa con los derechos y obligaciones personales del arrendador y arrendatario durante ese período? Especialmente importante, y de hecho el que más problemas ha suscitado, es el derecho del arrendador a percibir el precio y la obligación correlativa del arrendatario de pagar la renta de arrendamiento.

Una primera situación se produce en los casos en que, según el artículo 1962 del Código Civil, ya transcrito, el adquirente del derecho real sobre la cosa arrendada está obligado a respetar el arriendo. En esta hipótesis, el arriendo no expira por la extinción del derecho del arrendador $y$, por ende, éste conserva su derecho a percibir y el arrendatario sigue obligado a pagar al arrendador la renta de arrendamiento, conforme a las estipulaciones del contrato de arrendamiento que sigue vigente. 
Alberto Viada Lozano - Disquisición en Torno a la Extinción del Derecho del...

Un segundo caso es aquél en que el arrendador, junto con transferir o devolver el derecho real sobre la cosa arrendada, cede al tercero que lo adquiere o recupera sus derechos personales derivados del contrato de arrendamiento, conforme a las normas de cesión de créditos establecidas en el Párrafo 1 del Título XXV del Libro IV del Código Civil. En este caso tampoco expira el contrato de arrendamiento, sino que el tercero pasa a ocupar la calidad de arrendador y el arrendatario, por ende, deberá cumplir sus obligaciones, como la de pagar la renta, al nuevo titular del derecho, desde que se le notifique la cesión del crédito.

Pero el caso de mayor ocurrencia es el del tercero que sólo adquiere el derecho real sobre la cosa arrendada y no está obligado a respetar el arriendo, pero el contrato de arrendamiento subsiste hasta que se declare expirado por sentencia judicial. Aunque. en el contrato de compraventa se exprese que la cosa se vende "con todos sus derechos...etc....", ello no comprende el derecho personal del arrendador, salvo alguna cláusula especial de cesión de dicho crédito en forma, como se analizó en el párrafo precedente, sino que lo que se vende es el derecho real de dominio. Entonces, mientras. subsiste el arriendo, el arrendatario sigue obligado a pagar el precio al arrendador; por su parte el tercero adquirente del derecho real reclama que el ocupante del inmueble le pague la renta mientras no lo restituya, pero jurídicamente no tiene derecho a ello por no ser arrendador; y en algunos casos el arrendador no quiere recibir la renta, por haberse extinguido su derecho real sobre la cosa arrendada.

Este conflicto es una justificación más de la norma que obliga al tercero a demandar al arrendador, pues de éste deriva el derecho real que pretende hacer valer y es quien deberá responderle al tercero de los perjuicios que le irrogue el no poder ejercer plenamente ese derecho real sobre la cosa, por mantener su tenencia el arrendatario. Por su parte éste, que no tiene ningún vínculo jurídico con el tercero, no puede pagarle las rentas que se devenguen hasta que se declare expirado el arriendo, so pena de pagar a quien no corresponde $y$, como sabemos, siguiendo el conocido aforismo: "quien paga mal, paga dos veces". Y si convinieren el tercero y el arrendatario en que éste le pague a aquél las rentas de arrendamiento, no existiendo cesión en forma de sus derechos personales por parte del arrendador, se producirá la celebración de un nuevo contrato de arrendamiento entre el tercero y el arrendatario, sujeto al reclamo del arrendador exigiendo su derecho personal al no haberse declarado expirado el contrato de arrendamiento que él celebró con el arrendatario.

Este galimatías ha confundido algunas veces a los sentenciadores. Por ejemplo, recuerdo el siguiente caso: Una sociedad mercantil, arrendataria antigua del local donde funcionaba su establecimiento comercial, al fallecer su arrendador celebró un nuevo contrato de arrendamiento con el albacea testamentario por diez años renovables, mediante escritura pública que se inscribió en el registro conservatorio pertinente. Antes de cumplirse el plazo pactado, el partidor vendió el inmueble en que estaba ubicado el local a una sociedad inmobiliaria, la que demandó a la arrendataria pidiendo la restitución del local por haber expirado el arriendo al haberse extinguido el derecho del arrendador. Planteada la excepción de obligación de respetar el arriendo, conforme al artículo 1962 del Código Civil, tantas veces citado, la inmobiliaria demandó en otro tribunal la terminación del contrato por el no pago de las rentas, previas las reconvenciones legales, y el pago de las mismas devengadas y por devengarse hasta la restitución del local. A esta pretensión se opuso la arrendataria alegando que la inmobiliaria no era titular del derecho personal del arrendador a percibir el precio del arriendo ni a 
Revista de Derecho de la Universidad Católica del Norte Sede Coquimbo - 1999

ejercer la acción propia de la condición resolutoria tácita envuelta en el contrato de arrendamiento $y$, a mayor abundamiento, que las rentas estaban total y oportunamente pagadas al arrendador, el albacea testamentario, las últimas mediante pago por consignación en el Servicio de Tesorerías establecido en el artículo 23 de la ley 18.101. Antes de dictarse sentencia se acumularon ambos procesos y en su fallo el sentenciador reconoció la obligación de respetar el arriendo hasta la fecha de término pactada, declarándolo expirado por la causal del № 3ํ del artículo 1.950 del Código Civil; negó lugar a la terminación del contrato por la supuesta falta de pago de las rentas, porque el arriendo había expirado por la extinción del derecho del arrendador "con anterioridad, no pudiendo, en consecuencia, volver a declarar su extinción por una causal distinta y posterior", y, en lo que se refiere al pago de las rentas devengadas y por devengarse hasta la restitución del local, razonó así: "Que al haberse notificado personalmente al representante de la sociedad demandada de la demanda de restitución por extinción del derecho del arrendador, de fs. 10, con fecha 9 de septiembre de 1995, según consta de la certificación estampada por el ministro de fe, a fojas 12 vta., lo que permite presumir que desde esa fecha estaba en conocimiento que su arrendador había enajenado el bien raíz a la actora, por lo que, los pagos efectuados a contar del mes de octubre de 1995 a aquél, carecen de todo valor liberatorio, de acuerdo a lo estipulado en el artículo 1.576 del Código Civil, por lo que procede acoger esta demanda, en la parte que solicita el pago de las renta insolutas...".

Se percibe claramente de lo expuesto la confusión habitual entre el "derecho real " del arrendador sobre la cosa arrendada, que se extinguió al pasar el inmueble al dominio de la sociedad compradora, no por la venta sino por la tradición al inscribirse lo comprado en el registro conservatorio pertinente a nombre de la compradora, y el "derecho personal" del mismo arrendador, que en este caso no expiró, por tratarse de uno de aquéllos en que el nuevo titular del derecho real está obligado a respetar el arriendo, conforme al artículo 1962 del Código Civil. En estricto derecho, el contrato de arrendamiento debía terminar por la expiración del tiempo estipulado para la duración del arriendo, causal $2^{a}$ contemplada en el artículo 1.950 del mismo Código. En cuanto al pago de las rentas de arrendamiento, también se confunde el "derecho real" extinguido con el "derecho personal" o "crédito" del arrendador, lo que aparece de manifiesto al citar el sentenciador el artículo 1.576 del Código Civil, que dispone: "Para que el pago sea válido, debe hacerse $o$ al acreedor mismo (bajo cuyo nombre se entienden todos los que le hayan sucedido en el crédito, aún a título singular), o a la persona que la ley o el juez autoricen a recibir por él, o a la persona disputada por el acreedor para el cobro". En el ejemplo en estudio, como en la casi totalidad de ventas de inmueble por el arrendador, sólo se vendió y transfirió el derecho real del dominio, pero no se hizo ninguna cesión del crédito o derecho personal del arrendador, ni éste diputó a la actora para cobrar las rentas. Por consiguiente, la notificación de la demanda de restitución por extinción del derecho del arrendador sólo sirvió para que el arrendatario tuviere conocimiento de la venta y transferencia del derecho real de dominio sobre el inmueble, pero no constituye una notificación formal de una cesión del crédito o derecho personal del arrendador, porque tal cesión no existió, $y$, de haber existido, no podría ponerse término al contrato por el modo establecido en el № $3^{\circ}$ del artículo 1.950 del Código
Civil. 
Alberto Viada Lozano - Disquisición en Torno a la Extinción del Derecho del...

En definitiva, recapitulando sobre la materia tratada en este trabajo, tenemos que distinguir entre el "derecho real" que el arrendador tuviera sobre la cosa arrendada y el "derecho personal" o "crédito" que emana del contrato de arrendamiento. Extinguido el "derecho real" del arrendador sobre la cosa arrendada, puede expirar el arriendo por dicha causal, lo que no se produce por el solo ministerio de la ley, sino que será necesaria una sentencia judicial que así lo declare. $Y$ no se producirá la expiración del arriendo, a pesar de haberse extinguido el derecho real del arrendador sobre la cosa arrendada, principaimente cuando el arrendador, además del derecho real, haya cedido en forma al tercero su crédito o derecho personal emanado del contrato de arrendamiento, y también cuando el tercero adquirente del derecho real esté obligado a respetar el arriendo, conforme a lo dispuesto en el artículo 1.962 del Código Civil.

Como el arrendatario no tiene ningún vínculo jurídico con el tercero adquirente del derecho real sobre la cosa arrendada, a menos que el arrendador le hubiere cedido también su crédito o derecho personal, el tercero no podrá accionar en su contra pretendiendo el cumplimiento o terminación del contrato de arrendamiento, sino que deberá ejercer su acción pretendiendo lo propio de ese derecho real de que es titular, especialmente que se declare expirado el arriendo que impide, entraba o entorpece el ejercicio de las facultades propias de $5 L$ derecho real, esgrimiendo lógicamente el modo contemplado en el № $3^{\circ}$ del artículo 1950, esto es: la extinción del derecho real del arrendador sobre la cosa arrendada. $\mathrm{Y}$ al ejercer su acción pretendiendo su derecho real sobre la cosa arrendada, deberá entablar la demanda en contra del arrendador, conforme a lo establecido en el inciso primero del artículo 1.931 del Código Civil, sin perjuicjo de demandar también al arrendatario porque le afectará lo resuelto y para solicitar la restitución de la cosa arrendada como consecuencia de declararse expirado el arrienclo. Y si demandare únicamente al arrendatario, éste deberá citar de evicción a su arrendador, para que cumpla con su obligación de librarlo de toda privación, turbación o embarazo en el goce de la cosa arrendada, o responda de los perjuicios que de ello se derivaren para el arrendatario.

En cuanto a las obligaciones que del contrato de arrendamiento surgieren para el arrendatario, especialmente las de pagar oportunamente el precio, como sólo está obligado al arrendador, su contraparte del contrato, deberá seguir cumpliéndolas conforme a lo estipulado, pagando directamente al arrendador con quien contrató, a menos que éste hubiera también cedido su derecho personal o crédito, o hubiera disputado para el cobro al tercero, pero en ambos casos estaría pagando siempre al arrendador, sea como cesionario del crédito o a través del mandatario para el cobro. Y estas obligaciones subsistirán, como también sus derechos al goce de la cosa arrendada, hasta que la o las sentencias judiciales declaren expirado el arriendo y ordenen la restitución correspondiente. 
